\title{
Improving demand forecasting in the air cargo handling industry: A case study
}

\author{
Uriel Magaña Olmos \\ Logistics Specialist - Raw Material Management \\ Kromberg \& Schubert \\ Abensberg, Germany \\ S. Afshin Mansouri (Corresponding author) \\ Professor of Operations and Supply Chain Management \\ Brunel Business School, Brunel University London, \\ Uxbridge UB8 3PH, United Kingdom \\ Email: Afshin.Mansouri@ brunel.ac.uk \\ Tel: +44-1895-265-361 \\ Virginia L. M. Spiegler \\ Lecturer in Operations and Supply Chain Management \\ Kent Business School \\ University of Kent, United Kingdom
}

\begin{abstract}
Air transportation plays a crucial role in the agile and dynamic environment of contemporary supply chains. This industry is characterized by high air cargo demand uncertainty, making forecasting extremely challenging. An in-depth case-study has been undertaken in order to explore and untangle the factors influencing demand forecasting and consequently to improve the operational performance of an Air Cargo Handling Company. It has been identified that in practice, the demand forecasting process does not provide the necessary level of accuracy, to effectively cope with the high demand uncertainty. This has a negative impact on a whole range of air cargo operations, but especially on the management of the workforce, which is the most expensive resource in the air cargo handling industry. Besides forecast inaccuracy, a range of additional hidden factors that affect operations management have been identified. A number of recommendations have been made to improve demand forecasting and workforce management.
\end{abstract}

Keywords: Air cargo industry, Transportation forecasting, Operational performance, Workforce management, Case study 


\section{Introduction}

Demand forecasting is critical for any organization. However, in an uncertain economic environment, forecast accuracy has become an immense challenge (Davydenko \& Fildes, 2013, Wu, 2011). Early studies have already ascertained that effective forecasting is generally translated into organizational performance improvements (Sanders, 1995). Hence, customer demand forecasting is a key driver for effective supply chain management (SCM) (Stapleton et al., 2006, p. 110). With the growth of international trade, globalization and the tendency of companies to adopt inventory reduction along with the growing trend to implement SCM strategies focused on shorter lead times, the importance of demand forecasting in the framework of the air cargo industry is even more significant (Kasilingam, 1996; Hill, 2011). On the other hand, current negative economic factors such as global economic instability and volatile fuel prices (BOEING, 2012), intensify the need for an accurate and efficient air cargo demand forecasting and appropriate operations strategies even further.

Despite the increasing importance of airfreight services in agile era, most studies that intended to determine the practical implication of demand forecasting over the operational performance of companies, are mainly focused on manufacturing organizations (Acar \& Gardner Jr., 2012; Fildes \& Kingsman, 2011; Poler et al., 2008; Stapleton et al., 2006), retailing (Lau, 2012) and the trading environment (Adebanjo, 2009). A notable exception is Wu (2011), who proposes a model to cope with the high air cargo demand uncertainty. Air cargo demand uncertainty hampers an effective and efficient management of air cargo operations, therefore it "dramatically increases costs" (Fildes \& Kingsman, 2011). Among the whole range of air cargo operations, the workforce management in particular is highly affected by an inaccurate demand forecasting (Rong \& Grunow, 2009; Lagodimos \& Paravantis, 2006; Yan et al., 2006; Nobert \& Roy, 1998). In practice, this activity represents a weekly challenge for operations managers at air cargo terminals who are responsible for the workforce planning to support the cargo operations. Since workforce is the main resource of air cargo handling companies (ACHC), this research intends to inductively build a number of propositions to identify the factors influencing the demand forecasting process and consequently, to improve operational performance in terms of workforce management. This is hugely important because a better management of the workforce will decrease the manpower costs, which absorb the largest proportion of the total air cargo operating costs (IATA, 2013; Rong \& Grunow, 2009; Yan et al., 2006). 
The research in this paper was carried out in conjunction with a major ACHC operating at one of the largest air cargo terminals in Europe: London Heathrow Airport. As Fildes et al. (2009) have highlighted, there is a need to further undertake interpretative research in the domain of demand forecasting, "to establish, at a deep level, the beliefs and values of managers engaged in forecasting". Moreover, the literature reports that, despite efforts to develop sales forecasting techniques that accurately reproduce real business conditions, there is an existing gap between theory and practice that should be addressed by qualitatively examining organizational factors influencing demand forecasting (Davis \& Mentzer, 2007). This research will address these shortcomings in the literature. This research aims to examine factors influencing demand forecasting in the air cargo industry using an in-depth single casestudy with one of the authors of the paper embedded in the case company. Moreover, this research aims at identifying the impact of demand forecasting on workforce management, generating propositions and recommendations that can be translated into improved operational performances.

\section{Literature review}

\subsection{Contemporary air cargo supply chains}

A physical air cargo supply chain typically consists of three entities (Totamane et al., 2012; Popescu et al., 2006):

- Shippers, who are embodied by the customers of the air cargo services offered by Airlines.

- Freight forwarders, who are responsible for the physical movement (generally ground transportation) of the cargo, to and from the shippers' facilities.

- Airlines, the last link of the chain, are those that carry the actual cargo by air.

However, provided the general trend of present-day companies towards the outsourcing of non-core but critical functions, such as logistics (McIvor, 2009) many Airlines actually outsource the management of their air cargo operations to specialized ACHC (IATA, 2013; Nelms, 1999), which act as a 3PL for the Airlines. This strategy allows them to focus and employ their resources in the core competencies that generate their competitive advantage (McIvor, 2008), because the Airlines' core business is not air cargo handling, but air passenger transportation (Amaruchkul \& Lorchirachoonkul, 2011; Popescu et al., 2006; Nelms, 1999). Thus, an additional link in an air cargo supply chain that is not considered as such in the literature, is represented by the ACHCs, which are the basis of the case-study in 
this research (see Figure 1). ACHCs have several functions, ranging from physical operations such as pick-up and cargo delivery, consolidation, warehousing, sorting, loading, unloading; as well as administrative operations such as bookings, documentation, insurance, tracing, etc. (Wu, 2011; Nobert \& Roy, 1998).

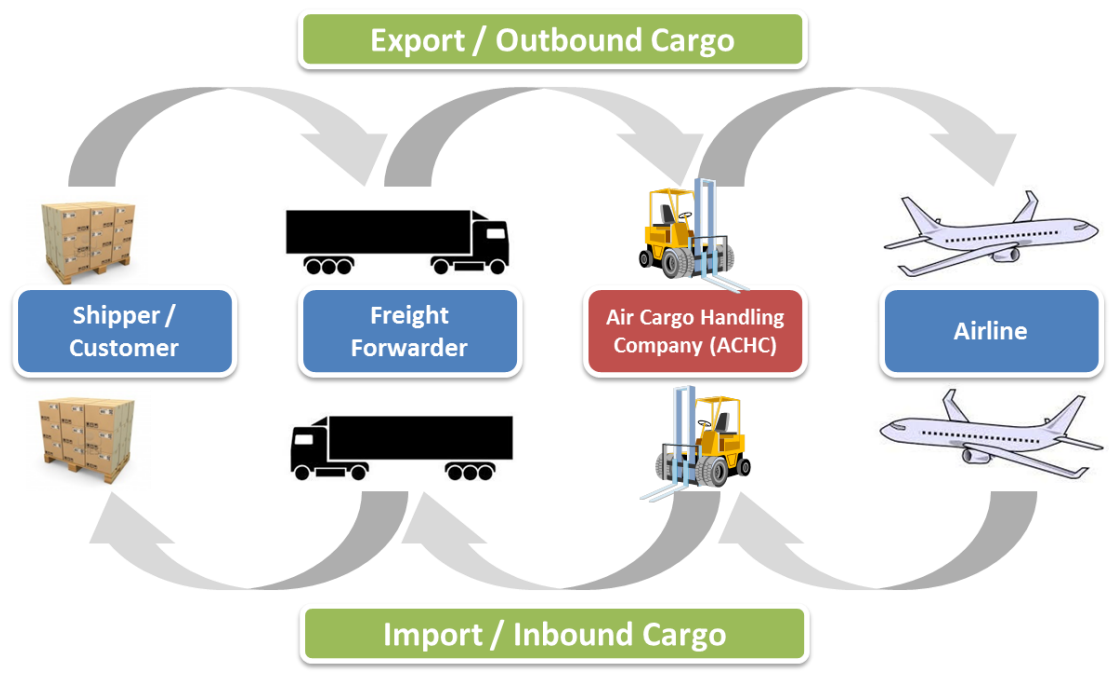

Figure 1. Air Cargo Supply Chain highlighting in red the ACHC

The rough sequence of operations at ACHCs according to Rong \& Grunow (2009) and Nobert \& Roy (1998) is the following: As for outbound cargo, once the freight has been delivered at the air cargo terminal by the freight forwarders or by the shipper itself, ACHC's operators unload the freight from the hauling vehicle and check the documentation. Subsequently, an airwaybill is prepared, the freight is sorted depending on its destination and, if necessary, the freight is consolidated into containers that are built-up by terminal operators. Finally the freight is taken to the loading area and once its flight is ready, it is transported to the airside and loaded into the aircraft. As for the inbound cargo, the process is very similar, but instead of containers being built-up, these are broken-down, if necessary.

\subsection{Challenges of demand forecasting in the air cargo industry}

Demand management is a constituent process of SCM (Chopra \& Meindl, 2013; Nakano, 2009). Early research has already established that, in light of the uncertainty of the environment in which companies operate, managers are constantly looking for ways to predict future customer demand (Sanders, 1995; Waddell \& Sohal, 1994), which is when forecasting comes into play (Lysons \& Farrington, 2012). 
The current supply chain context of the air cargo industry suggests a latent necessity to forecast air cargo demand in an efficient and accurate manner. The versatility of the air cargo operations environment (Hsu et al., 2013) makes the adoption of an efficient forecasting method more complicated (Waddell \& Sohal, 1994). Thus, effective air cargo demand forecasting is vital, provided its influence over the conduction of a company's operations (Becker \& Wald, 2010). There are some other authors (Chou et al., 2013; Chen et al., 2012; Suryani et al., 2012) that undertake research towards enhancing the forecasts accuracy of air cargo demand, mainly in the long-run, from a broader macroeconomic perspective, taking into consideration factors such as population, employment rates, incomes per capita, GDP, GNP, economic growth rates, etc. However, the root cause that prevents forecasts from being accurate in this industry, is simply the uncertain and volatile nature of air cargo demand (Totamane et al., 2012; Amaruchkul et al., 2011; Wu, 2011; Popescu et al., 2006). A big proportion of which, is due to the heterogeneity factor in customer demand, as described by Kalchschmidt et al. (2006). Demand fluctuations in the air cargo industry impede an optimum network design and reliability of operations (Hsu \& Wang, 2013).

\subsection{Relevant air cargo demand forecasting methods}

According to the existing literature, Airlines and ACHCs have employed a wide range of forecasting methods over time, due to the diversity of challenges in air cargo demand and operations previously exposed. However, it has been found as well, that the literature has exclusively focused on the study of demand forecasting methods that can be categorized as analytical or 'quantitative' as per Lysons \& Farrington (2012), overlooking the exploration and applicability of 'qualitative' methods. In that sense, the following are the main analytical methods identified in the existing literature on air cargo demand forecasting:

- Exponential smoothing (Fildes et al., 2009; Kasilingam, 1996)

- Time series analysis (Chen et al., 2012; Suryani et al., 2012)

- Econometric modelling (BOEING, 2012; Chen et al., 2012; Totamane et al., 2012)

- Trend analysis (BOEING, 2012; Totamane et al., 2012)

- Seasonality indices (Kasilingam, 1996)

Although sophisticated quantitative forecasting methods are available, many forecasting processes still rely on human assessments and decisions (Lawrence et al. 2006). As for the 
qualitative forecasting methods, collaborative and judgmental forecasting techniques are normally used.

\subsubsection{Collaborative forecasting}

According to previous studies, collaboration in a supply chain starts from integration (Nakano, 2009) which mainly refers to the merging of business and information flow processes, sharing of resources and joint goals setting (Kahn \& Mentzer, 1996). Moreover a strong connection has been found between collaboration and improvements in performance (Hung et al., 2014; Ramanathan, 2012; Wook Kim, 2006; Barratt, 2004; Stank et al., 2001). Thus, the implementation of collaborative forecasting initiatives "can provide substantial benefits to the supply chain, but the magnitude of these benefits depends on the specific setting" (Aviv, 2001, p. 1339).

Hence, the integration of 'forecasting' and consequently of 'planning' processes, has an effect on logistics performance according to Nakano (2009), and today's global players are indeed creating strong relationships with customers and suppliers (Stank et al., 2001). It has been even claimed that the integration of business processes (Nakano, 2009) and the use of supply chain collaboration strategies (Ramanathan, 2012) are the best means to achieve competitive advantage and success in a supply chain.

On a very basic principle, a collaborative forecasting approach should firstly be aimed at tackling two fundamental aspects according to Aviv (2001): the procedure for demand-related information sharing, and the procedure to incorporate that information and the combined forecasting practice into the company's operational policies. Ramanathan (2012) stresses in its paper, that the decision on what information exactly to share with supply chain partners is a delicate one, which must be carefully taken in order to ensure an accurate demand forecast, suggesting that not all information is useful for this purpose. In this sense, two dimensions of collaboration have to be considered (Nakano, 2009):

- internal collaboration, the one between the different departments within an organisation.

- external collaboration, the one between external suppliers and customers.

Stank et al. (2001) argue that if a company wants to achieve a competitive advantage by means of external collaboration, it must enhance the collaboration on its internal processes at 
the same time, since this allows an accurate response to customer requirements. This supports the statement of Barratt (2004) that improvements in internal and in external collaboration must be simultaneously approached. Nevertheless, Nakano (2009) found that logistics performance is more affected by internal than by external collaboration. This was already determined to a certain extent by Ellinger et al. (2000), who showed a predominantly positive relationship between the degree of collaboration of the internal dyad sales/logistics, and the level of operational performance. However, Barratt (2004) suggests that internal collaboration can be pretty problematic due to frictions that may exist between functional departments within a company.

Previously, Stank et al. (2001) had found as well that collaboration with external partners (customers and suppliers) consequently enhances the degree of internal collaboration, which certainly impacts the operational performance in a positive manner. So, in the framework of air cargo handling, Airlines and ACHCs attain high levels of competitiveness by collaborating with external partners (customers), which improves their internal understanding over customer demands (Totamane et al., 2012). In conclusion, even though collaboration can bring significant benefits in terms of operational performance, it is indeed difficult to implement, because of the amount of resources that must be committed to do so (Barratt, 2004).

\subsubsection{Judgmental forecasting}

Typically, analytical forecasting methods used by companies in a supply chain, are subject to adjustments derived from the expert knowledge of the organization's managers (Davydenko $\&$ Fildes, 2013). Such adjustments may be necessary due to deficiencies in the system used to forecast or to incorporate future unconventional events; all of which can be foreseen by managers, demand planners (Fildes et al., 2009), or people with advanced knowledge over the product/service and the market. Thus, forecasters usually check the outcome of their analytical or historical forecasts, and they adjust them as required based on their knowledge about market conditions, future trends and other contextual information (Marmier \& Cheikhrouhou, 2010). In order to first identify the potential factors to be judgmentally incorporated into forecasts, Marmier \& Cheikhrouhou (2010) suggest to compare those potential factors against the following characteristics:

- the occurrence is irregular and intermittent 
- the impact is such that it cannot be ignored

- the impact is either transitory or of changing nature

- the event can be detected by experts before it occurs

If any factor complies with these characteristics, it should be included into the forecast judgmentally. For some authors (Fildes \& Goodwin, 2007) this action is even more vital for optimizing the forecast than other mathematical measures for the same purpose. Although there was some degree of reluctance among researchers in the past regarding the use of judgements in forecasting, nowadays it is encouraged to apply judgements along with other analytical techniques to increase the accuracy level of forecasts (Lawrence et al., 2006). However, in order for judgemental adjustments to positively influence the forecast accuracy, a structured process to incorporate them should be implemented (Fildes \& Goodwin, 2007). This would allow:

- a better evaluation of judgements,

- a step to revise them according to feedback received from other departments,

- to formally document adjustments made in order to have a record that could save time and resources when forecasting customer demand in subsequent periods.

Hence, human judgement comes into play when quantitative methods of forecasting lack the capability of quickly identifying changes and modifications in the predictions previously made; besides, human judgement provides a better translation of those changes in subsequent scenarios (Waddell \& Sohal, 1994). That is why a mixture of quantitative and qualitative forecasing methods could substantially improve the outcome of forecasts (Chen et al., 2012).

In this specific study, the volatile nature of the air cargo demand is an important issue that has to be carefully approached, because according to Fildes et al. (2009), judgemental adjustments are more challenging to implement under volatile conditions. In the case of the air cargo industry, Popescu et al. (2006) claim that investments in demand forecasting methods are necessary, for the sake of an optimal utilization of cargo capacity and because of the considerable revenue that air freight transportation generates (Kasilingam, 1996).

\subsection{Forecasting and workforce management in air cargo operations}


Early research has already noticed that companies have difficulties in accurately calculating the number of staff required to achieve their business objectives (Ward, 1996), and the air transportation industry is apparently not the exception (Rong \& Grunow, 2009). In the context of this study, the relationship between an effective workforce planning and the inaccuracy of demand forecasts has to be explored. In fact, the scheduling of manpower to take care of cargo handling operations at air cargo terminals is a huge challenge. Partly, due to the uncertainty of the air cargo industry discussed above (Totamane et al., 2012; Amaruchkul et al., 2011; Wu, 2011; Popescu et al., 2006) and due to the high variations of flight departures and arrivals at airports, along with the fact that staff must be employed in full shifts, regardless of the variable workloads at different hours during the day in conventional air cargo terminals (Rong \& Grunow, 2009).

Moreover, Yan et al. (2006) determine that efficient cargo operations, high levels of service and reductions of other operating costs, could all be very well achieved through an effective workforce management. Provided that manpower costs can represent as much as $70 \%$ of the total of cargo handling costs (IATA, 2013), an accurate forecasting of air cargo demand is crucial. Operationally, there are two extremes of air cargo demand uncertainty described by Popescu et al. (2006), that negatively affect the management of the workforce:

- 'spoilages', that refer to the situation when the volumes of cargo handled were lower than expected, which results in having idle staff.

- 'off-loads', that refer to the opposite situation, when the volumes of cargo handled were higher than expected, which results in running short of staff to take care of the excess cargo.

Considering the latter, early studies (Ward, 1996) have already proposed a number of basic techniques to forecast the workforce required, that could contribute to mitigate the abovementioned issues, such as historical forecasting, process analysis and the implementation of statistical methods. Nevertheless, although some recent studies (Rong \& Grunow, 2009; Yan et al., 2006) also make positive contributions towards an effective management of the workforce at air cargo terminals, they still take historical data alone, as the basis for the calculations of their proposed models, failing to focus on the future regardless of what has happened in the past. Moreover, a weakness of the research by Yan et al. (2006) lies 
on the assumption of a certain degree of determinism in the demand for manpower, which is in practice highly stochastic.

\section{Research methodology}

As previously mentioned, an in-depth case-study was carried out in conjunction with specialized ACHC where one of the authors was embedded as a reflective practitioner. The company is present in over 120 airports in around 20 countries across Europe, North America, Asia, Africa and the Middle East, making it one of the largest ACHCs in the world. The study was particularly focused on the operations at the London Heathrow Airport cargo terminal, but in order to enhance the level of representativeness of the research, information from other company hubs across the UK and some other across Europe was taken into account as well.

Additionally, with over 30 years of history in the air cargo business and a workforce of over 10,000 employees, the case company manages air cargo operations for over 300 Airlines globally. Besides the wide range of cargo handling services, the company offers Airlines other ground handling and technical services as well. The knowledge generated by this research entails a high level of representativeness and generalizability, provided the size of the case-study company and the fact that it is based in Heathrow Airport, which is the world's busiest international airport. In order to gather the relevant data to conduct this research, we employed three main research instruments: participant observation and ethnography, secondary data through documents and reports and semi-structured interviews.

A very similar set of research instruments was used in comparable research papers on demand forecasting management from highly ranked academic journals (Lau, 2012; Stratton, 2012; Choi \& Hong, 2002), which supports the viability of this set of instruments to provide effective results.

\subsection{Participant observation and ethnography}

A "participant observer/ethnographer immerses him or herself in a group for an extended period of time, observing behaviour, listening to what is said in conversations both between others and with the fieldworker, and asking questions" (Bryman \& Bell, 2011). One of the authors of this research has embedded himself into the ACHC full-time during a 3 months period on a daily basis. This allowed a comprehensive and intensive data collection, including on-site observations of business processes, demand forecasting practices, operational 
challenges and execution of operations in terms of workforce management; and a factual interpretation afterwards.

The ethnographer role taken in the ACHC was that of 'participant-as-observer' (Gold, 1958), who possesses a specific function within the organisation under investigation and whose presence as a 'researcher' is known by the other staff members. In this setting, the staff is open to contribute to the ethnographer's research through regular interaction with him.

In this sense, the specific function of the researcher within the organisation was the gathering and analysis of data from the different departments to create the business reports and scorecards, with which the company measures the operational performance of the business. This function allowed using a combination of 'purposive' and 'snowball sampling' for selecting the relevant research informants and the conduction of the subsequent data collection method.

\subsection{Documents and reports as data sources}

The data gathered and subsequently analysed for this research, came mainly from business reports with which the management of the company makes operational decisions in terms of throughputs, service levels, productivity, costs control and workforce management.

The main use of this data collection instrument was to determine the specific operational challenges of the company in terms of performance and to untangle their quantitative impact on the company's performance indicators. Special attention for this specific research was paid on workforce/manpower management reports.

\subsection{Semi-structured interviews}

Although the ethnographic data collection already included a considerable amount of unstructured interviewing, a number of semi-structured interviews were conducted as well. These allowed carrying out guided but flexible conversations with some staff members who represented main sources of information.

The interviewees were selected purposively; meaning that they were strategically chosen based on their relevance to contribute to the different stages of the research. The actual interviews were conducted using an 'interview guide' (see Appendix A). Moreover, in order to avoid omitting any important details during the actual interviews and to enable a reliable 
and exhaustive data analysis afterwards, the interviews were recorded with a smartphone's voice recording application and simultaneously notes of the most important points were taken. Among the interviewees, there were three directors, three operations managers, two human resources managers and two airline representatives. It is worth reiterating that the ethnographic data collection already included a considerable amount of unstructured interviewing with several other staff members in addition to those collected in this phase.

The rationale for conducting semi-structured interviews on top of the other two data collection instruments lied as well on the necessity to confirm the validity and reliability of the data collected and to corroborate whether these data represented the actual status-quo. In other words, the validity of the observations and interpretations from the previous two data collection methods was tested with interview questions, which is known as a 'triangulation strategy'. Besides, a couple of questions were strategically selected to be asked in the same way to interviewees from very different areas and backgrounds so as to further prove the reliability and veracity of the data.

Lastly, it is worth mentioning that the ethnographic data collection that involved an immersion of the researcher into the case-study company over a long period of time, granted a high level of congruence between concepts and observations, which further contributed to the data validity and reliability.

\section{Status-quo of demand forecasting process at ACHCs}

Unlike the manufacturing industry for example, where forecasts are calculated in 'units to produce', in the air cargo industry, forecasts are calculated in 'tonnes to handle'. Interestingly, it has been found that in practice, Airlines do not only outsource the actual physical cargo operations management to ACHCs, but they outsource the demand forecasting function as well, so that ACHCs partially act as a 4PL (Win, 2008). Hence, ACHCs are directly responsible to predict the tonnages of cargo to handle per month and per customer (Airline), so as to plan the necessary resources to support the operation.

Thus, each year forecasters at ACHCs calculate or, as it is usually referred to in practice, 'budget' the tonnages of cargo to handle per month and per Airline for the subsequent year. This forecasting/budgeting process is done exclusively based on historical data and partly on information from Airlines that may or may not be available as a result of verbal 
communication between the senior management of the ACHC and Airline staff. Such information would be then used to adjust the forecasts based on the forecasters' judgement, which have been previously defined as 'judgmental adjustments' in Section 2.3. According to Fildes et al. (2009), forecasts made in this way are prone to be inefficient. Hence, the historical analysis to generate the budgeted tonnages to handle is done on a spread-sheet as in Table 1.

\begin{tabular}{l|l|l|l|l|l|l|l|l|l|l|l} 
Jan & Feb & Mar & Apr & May & Jun & Jul & Aug & Sep & Oct & Nov & Dec
\end{tabular}

\begin{tabular}{|l|c|c|c|c|c|c|c|c|c|c|c|c|c|}
\hline Imports - Airline X & \multicolumn{10}{|c|}{ X } \\
\hline $\mathbf{2 0 1 3}$ & Budget & 3503 & 3696 & 4247 & 3450 & 3627 & 3900 & 3565 & 3565 & 3750 & 4030 & 3900 & 3875 \\
\hline $\mathbf{2 0 1 2}$ & Actual tonnage & 3500 & 3917 & 4260 & 3459 & 3642 & 3883 & 3547 & 3458 & 3323 & 3720 & 3600 & 3720 \\
\hline $\mathbf{2 0 1 1}$ & Actual tonnage & 4276 & 4367 & 4915 & 4384 & 4721 & 4375 & 4410 & 3860 & 3885 & 3993 & 3431 & 3741 \\
\hline $\mathbf{2 0 1 0}$ & Actual tonnage & 4316 & 4080 & 4665 & 4006 & 5212 & 4419 & 4369 & 4252 & 4752 & 5510 & 4238 & 4147 \\
\hline $\mathbf{2 0 0 9}$ & Actual tonnage & 3736 & 3515 & 3991 & 3384 & 3916 & 3742 & 3685 & 4091 & 3906 & 4746 & 4623 & 4203 \\
\hline
\end{tabular}

\section{Exports - Airline $X$}

\begin{tabular}{|l|c|c|c|c|c|c|c|c|c|c|c|c|c|}
\hline $\mathbf{2 0 1 3}$ & Budget & 3720 & 3500 & 4402 & 4200 & 4185 & 3900 & 4805 & 4805 & 4650 & 4185 & 3900 & 3937 \\
\hline $\mathbf{2 0 1 2}$ & Actual tonnage & 3550 & 3653 & 4390 & 4610 & 4165 & 3842 & 4735 & 5065 & 4508 & 3813 & 3690 & 3813 \\
\hline $\mathbf{2 0 1 1}$ & Actual tonnage & 3683 & 3865 & 4627 & 4235 & 4582 & 3928 & 4510 & 4133 & 4349 & 3904 & 3871 & 3888 \\
\hline $\mathbf{2 0 1 0}$ & Actual tonnage & 3857 & 3666 & 4387 & 3636 & 5267 & 4987 & 5306 & 5132 & 5129 & 5026 & 4314 & 3872 \\
\hline $\mathbf{2 0 0 9}$ & Actual tonnage & 2974 & 3618 & 3790 & 4102 & 4421 & 4231 & 4028 & 4254 & 3884 & 4051 & 4300 & 4100 \\
\hline
\end{tabular}

Table 1. Historical or 'activity' analysis to produce forecast figures of tonnes to handle per month. Adapted from ACHC.

Moreover, it has been found that there is no established process or formal information flow whatsoever between Airlines and ACHCs, in order to incorporate the abovementioned adjustments into the forecasts in a methodical and structured manner. Surprisingly, it was found as well that experienced forecasters at ACHCs do not rely on Airlines' forecast figures at all, not even to get historical data, because their general view is that "Airlines are notoriously bad at doing their own figures, and they often don't know historical figures either" (Senior Manager). Nonetheless, ACHCs may receive some forecast figures from some Airlines, but because of the lack of a formal information flow process, the information is never received on time to allow ACHCs to produce its own budgets in a timely manner so as to plan its resources accordingly. Thus, forecasters at ACHCs may just "sense-check" the figures from the Airlines and adjust their own, again, based on their judgement.

In this sense, it has been found that forecasts are made almost in concealment purely based on historical data, so that there is a lack of joint decision-making between Airlines and ACHCs, an issue that was also stressed by Barratt (2004). Besides, contrary to expectations, a 
statement from over 18 years ago about forecasting being done judgementally and intuitively rather than in a more methodical and systematical manner (Waddell \& Sohal, 1994), has been found to be still valid in today's ACHCs.

\section{Status-quo of workforce management at ACHCs}

After demand has been forecasted, the resources to meet that demand must be planned accordingly, which is also known as capacity planning (Chopra \& Meindl, 2013). Thus, workforce (the most critical resource at ACHCs) is planned manually based on the forecasted tonnages to handle, according to the following calculation: 120 tonnes/ man / month. So, in a very basic principle, if the forecasted tonnage for Airline $X$ for the next month is 240 tonnes, the ACHC will need 2 men to handle those 240 tonnes next month. And that is basically how the 'rosters' of manpower hours are created. Operations managers take those rosters and adjust them on a weekly basis to plan exactly the number of staff they will require, taking into account several factors such as:

- The overall demand uncertainty.

- General absences due to sickness, holidays, trainings, maternity leaves, etc.

- Busiest days of the week depending on the Airline.

- Special requests from Airlines (e.g. cargo that has to be $100 \%$ screened and to go through a different safety procedure which is more manpower-intensive, etc.).

Thus, it is difficult to accurately plan the short-term rostering process at the operational level. Besides, it is done without using any kind of standardized process or software; hundredpercent manually, which makes it time-consuming, inaccurate, difficult to standardize and error-prone. This finding is consistent with that of Ernst et al. (2004), who found that the main reason is that companies believe that rostering software do not provide the level of flexibility required, so as to adapt them to the individual needs of their different workplaces.

In principle, operations managers have to balance their workforce so as to avoid having idle staff (too many) or running short of staff (insufficient). Although it has been found that both scenarios are negative and expensive, operationally, the latter is the most difficult to deal with. Deriving from this last point, it was found as well that in order for ACHCs to grant a certain level of flexibility to their operations, they use two strategies to cover any lack of staff: 
- An external recruiting agency

- Overtime hours

Interestingly, the HR department determined that "the reason for using a recruitment agency is only to fill a gap when regular permanent staff is absent mainly due to sickness or holidays" (Human Resources Manager) as is the use of overtime, and not to cover staff shortages as a result of the demand forecasting inaccuracy. However, other departments believe that ACHCs pay too much agency staffing and overtime, casting doubt on the HR's statement of the agency and overtime being used exclusively to cover absences due to sickness and holidays. Moreover, the quantitative analysis of one of the largest business units at the ACHC in Figure 2 further corroborated that assumption.

\begin{tabular}{|c|c|c|c|c|c|c|c|c|c|}
\hline Date & $\begin{array}{c}\text { Rostered } \\
\text { hrs }\end{array}$ & \multirow{8}{*}{ - } & Absences & $\begin{array}{l}\text { Available hrs } \\
\text { after absences }\end{array}$ & $\begin{array}{l}\text { Overtime hrs + } \\
\text { agency hrs used }\end{array}$ & $\begin{array}{c}\text { Actual hrs } \\
\text { worked }\end{array}$ & & $\begin{array}{c}\text { Excess } \\
\text { overtime used }\end{array}$ & $\begin{array}{c}\text { Diff } \\
\text { (times) }\end{array}$ \\
\hline Jan 2013 & $8,558.00$ & & 695.50 & $7,862.50$ & $2,257.25$ & $10,119.75$ & & $1,561.75$ & 2.25 \\
\hline Feb 2013 & $7,031.00$ & & $1,236.75$ & $5,794.25$ & $3,111.75$ & $8,906.00$ & & $1,875.00$ & 1.52 \\
\hline Mar 2013 & $9,073.00$ & & 903.00 & $8,170.00$ & $3,865.25$ & $12,035.25$ & $\bullet$ & $2,962.25$ & 3.28 \\
\hline Apr 2013 & $7,289.00$ & & 903.25 & $6,385.75$ & $3,648.50$ & $10,034.25$ & • & $2,745.25$ & 3.04 \\
\hline May 2013 & $7,106.00$ & & $1,075.25$ & $6,030.75$ & $4,030.75$ & $10,061.50$ & & $2,955.50$ & 2.75 \\
\hline Jun 2013 & $8,181.00$ & & $1,408.25$ & $6,772.75$ & $4,209.50$ & $10,982.25$ & & $2,801.25$ & 1.99 \\
\hline Jul 2013 & $7,611.00$ & & $1,375.75$ & $6,235.25$ & $3,968.00$ & $10,203.25$ & & $2,592.25$ & 1.88 \\
\hline
\end{tabular}

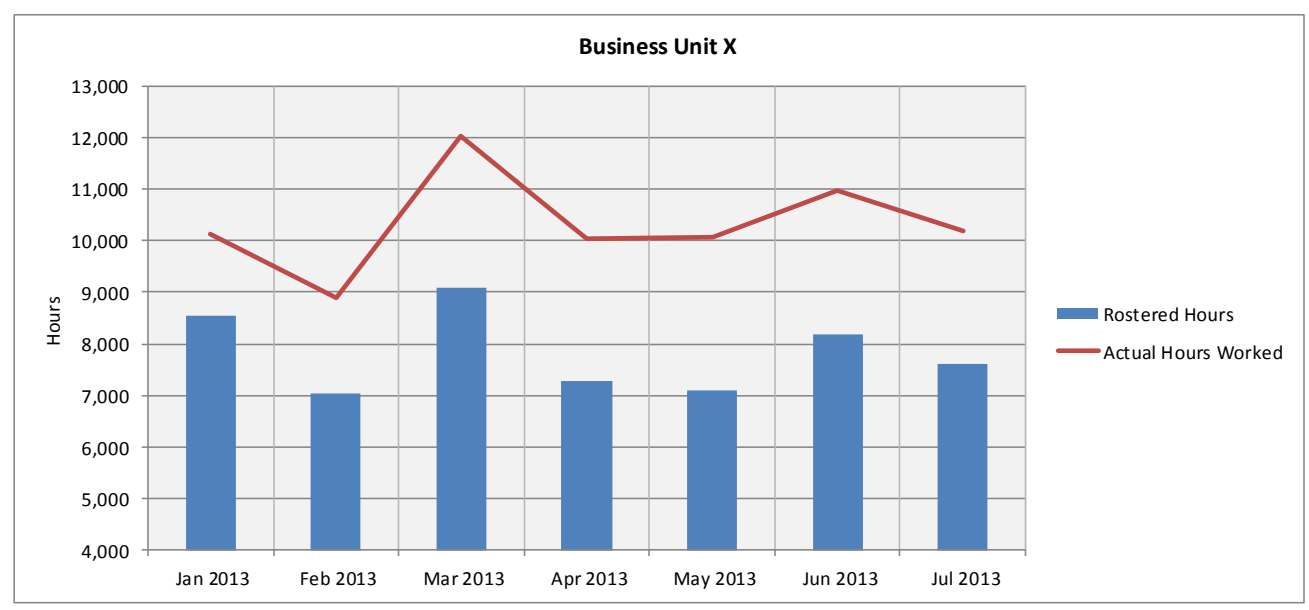

Figure 2. Gap analysis between rostered and actual hours worked and excess overtime used. Adapted from ACHC.

From the data in Figure 2, it can be clearly noticed that 'Overtime and agency hours used' are considerably higher than 'Absences', which suggests that in practice, the abovementioned flexibility strategies are not being exclusively used to cover sickness, holidays and other kinds of absences. Thus, there must be something else causing the 'Excess overtime used'. Hence, the gap between 'Actual hours worked' and 'Rostered hours' has to be narrowed. 
In contrast to earlier studies, it has been found as well that there is a general tendency to under-forecast, i.e. run operations with the less possible staff, which according to the views of operations managers and HR agents, is less expensive. This could partially explain the excess in overtime used. However, this strategy differs with the trend identified by Fildes \& Goodwin (2007) who showed that under-forecasting practices are generally more expensive, for example in the framework of the retail and the manufacturing industries.

Furthermore, besides the complexities of the weekly rostering process, the recording and reporting of the actual manpower hours "is such a pain" (Operations Manager) too, and it is done hundred-percent manually as well. Thus, it is somewhat surprising that something as critical as the workforce, is done completely manual and it is considered as one of the most complex activities to do. Not to mention that workforce represents the most important resource for ACHCs and the largest share of cargo handling operating costs (IATA, 2013; Rong \& Grunow, 2009; Yan et al., 2006). Moreover, from the HR point of view, it is believed as well that the main challenge in the rostering of manpower is at the short-term operational level: "it's such a fine line between not having too many staff and... if you talk to the staff on the floor they'll probably say: you've never got enough staff, we're always overworked” (Human Resources Manager). This statement suggests two issues:

- The calculation for having the right amount of staff is indeed a very difficult one.

- A further dimension to the workforce management complexity: the different perceptions of the people to the problem. It was found for instance, that operations management perceives a different accuracy level of the weekly manpower planning, compared to what figures say; i.e. operations management claims to meet their weekly rostering plans up to a $85 \%-90 \%$, but the figures reveal a considerable lower level of accuracy (sometimes as low as $40 \%$ ). This leads to discrepancies at the operational decision-making process.

Lastly, it is worth mentioning that because of the high uncertainty of the air cargo industry and further challenges discussed above, manpower planning must be sometimes adjusted on a daily basis. The following section, the most significant factors influencing both domains discussed above, 'demand forecasting' and 'workforce management', will be revealed. 


\section{Factors influencing demand forecasting and workforce management}

The data presented in the previous sections uncovered an interconnection of factors affecting 'forecast accuracy' and 'workforce management', which we summarise in Table 2. The results of the data analysis found 10 broad categories in which those factors have been grouped according to its nature. These are:

C1. Collaboration

C2. Communication

C3. Costs

C4. Information Systems

C5. Nature of the industry

C6. Outermost

C7. Processes

C8. Staff

C9. Supply Chain

C10. Training

Additionally, the analysis enabled to classify them as 'internal' and/or 'external' depending on the source of the problem and to identify further relevant attributes, some examples and other important remarks. Finally, the analysis allowed determining whether each factor can be manageable by ACHCs based on its attributes. According to Table 2, there are few factors that cannot be controlled by ACHCs in order to improve the forecast accuracy and the workforce management process. For instance, problems that relate to the nature of the industry and external aspects are less likely to be manageable by ACHCs. Few exceptions would be the heterogeneity of freights, which could be better managed by collaborating with Airlines to improve the information flow process; Health and Safety requirements and diversity of Service Level Agreements (SLA), which also depend on the heterogeneity factor. Other problems arising from sudden staff absence, changes in Airlines' customer demands and deficiencies in the Airlines' operations and processes are outside the control of ACHCs. 


\begin{tabular}{|c|c|c|c|c|c|c|c|}
\hline Categories & Factor descriptions & $\begin{array}{l}\text { Affects } \\
\text { forecast } \\
\text { accuracy }\end{array}$ & $\begin{array}{l}\text { Affects } \\
\text { workforce }\end{array}$ & Internal & External & Important remarks & $\begin{array}{l}\text { Manageable } \\
\text { by ACHCs? }\end{array}$ \\
\hline \multirow{7}{*}{ C1. Collaboration } & $\begin{array}{l}\text { Lack of communication between ACHCs } \\
\text { and Airlines }\end{array}$ & $x$ & $\mathrm{x}$ & $\mathrm{x}$ & $\mathrm{x}$ & $\begin{array}{l}\text { There is no information sharing of any kind that could help to improve } \\
\text { the forecast accuracy and consequently the workforce management }\end{array}$ & Yes \\
\hline & $\begin{array}{l}\text { Lack of a formal information flow process } \\
\text { from Airline towards ACHCs }\end{array}$ & $\mathrm{x}$ & & & $x$ & $\begin{array}{l}\text { "Airlines don't help out as much as they could" (Operations Manager)/ } \\
\text { ACHCs cannot plan according to airlines' plans, because there is no } \\
\text { information sharing due to confidentiality, etc. }\end{array}$ & Yes \\
\hline & $\begin{array}{l}\text { Unanticipated nature of extra-ordinary } \\
\text { customer requirements }\end{array}$ & $\mathrm{x}$ & & & $x$ & $\begin{array}{l}\text { E.g. Fragile freight that requires photos to be taken from every angle } \\
\text { when loading and unloading to and from the aircraft. }\end{array}$ & Yes \\
\hline & $\begin{array}{l}\text { Lack of communication between freight } \\
\text { forwarders and ACHCs }\end{array}$ & & $x$ & $\mathrm{x}$ & $x$ & $\begin{array}{lcccc}\begin{array}{l}\text { Sometimes, } \\
\text { this also translates in }\end{array} \text { unanticipated } & \text { time- } \\
\text { consuming/manpower-intensive operations }\end{array}$ & Yes \\
\hline & Limitations in Airlines' long term plans & $x$ & & & $x$ & $\begin{array}{l}\text { Airlines' long term plans are very "sketchy" (Senior Manager). Some } \\
\text { airlines admit explicitly that their internal forecasts are in average 60\%- } \\
70 \% \text { accurate (Airline Representative). }\end{array}$ & No \\
\hline & $\begin{array}{l}\text { Quality of the cargo information that } \\
\text { come from airlines }\end{array}$ & $x$ & $x$ & & $x$ & $\begin{array}{l}\text { Information is not detailed in any way and it does not contain any } \\
\text { specific break-down in terms of, for example, piece-count, number of } \\
\text { airway bills to process, etc. }\end{array}$ & Yes \\
\hline & $\begin{array}{l}\text { ACHCs predominantly deal with local } \\
\text { cargo management rather than with } \\
\text { senior management from the Airlines }\end{array}$ & $x$ & & $x$ & $x$ & $\begin{array}{l}\text { Local management does not know about Airlines' general plans, unless it } \\
\text { is going to affect them directly. }\end{array}$ & Yes \\
\hline \multirow{3}{*}{$\begin{array}{l}\mathrm{C} 2 \text {. } \\
\text { Communication }\end{array}$} & $\begin{array}{l}\text { Lack of communication between ACHCs' } \\
\text { business units/hubs at different location }\end{array}$ & $x$ & $x$ & $\mathrm{x}$ & & $\begin{array}{l}\text { E.g. full-flight-manifests (the document containing the break-down and } \\
\text { detailed cargo information) are not shared in a timely manner }\end{array}$ & Yes \\
\hline & $\begin{array}{l}\text { The way in which the operations } \\
\text { management team communicates with } \\
\text { the operational staff }\end{array}$ & & $x$ & $x$ & & $\begin{array}{l}\text { Effective communication is important, specially when operations } \\
\text { managers ask staff to do things outside contract parameters, which is } \\
\text { quite common in this industry }\end{array}$ & Yes \\
\hline & $\begin{array}{l}\text { Quality of communication within the } \\
\text { different departments at ACHC's }\end{array}$ & & $x$ & $x$ & & $\begin{array}{l}\text { Internally there is no established communication flow processes either, } \\
\text { thus, business information is not transmitted effectively within the } \\
\text { ACHC's department }\end{array}$ & Yes \\
\hline \multirow{3}{*}{ C3. Costs } & $\begin{array}{l}\text { ACHCs nave strong focus on saving } \\
\text { workforce costs }\end{array}$ & & $\mathrm{x}$ & $\mathrm{x}$ & & $\begin{array}{l}\text { The management wants to rigorously ensure that no staff is brought in } \\
\text { that is not actually needed }\end{array}$ & Yes \\
\hline & Airlines are nowadays very segregated & $\mathrm{x}$ & & & $\mathrm{x}$ & $\begin{array}{l}\text { That triggered a necessity for airlines to monitor air cargo operating } \\
\text { costs more closely, so that there is no longer customer-supplier } \\
\text { relationship based on trust }\end{array}$ & No \\
\hline & $\begin{array}{l}\text { Airlines perpetual tendency to save on } \\
\text { operational costs at any expense }\end{array}$ & & $\mathrm{x}$ & & $\mathrm{x}$ & $\begin{array}{l}\text { ACHCs absorb air cargo operating costs that airlines are not willing to } \\
\text { bear, e.g. manpower costs. }\end{array}$ & Yes \\
\hline \multirow{2}{*}{$\begin{array}{l}\text { C4. Information } \\
\text { Systems }\end{array}$} & $\begin{array}{l}\text { Different information systems used by the } \\
\text { different airlines }\end{array}$ & $\mathrm{x}$ & & & $x$ & This leads to huge discrepancies in operational information & Yes \\
\hline & $\begin{array}{l}\text { The airlines' incapability of using new } \\
\text { emerging information systems }\end{array}$ & $\mathrm{x}$ & & & $\mathrm{x}$ & This leads to huge discrepancies in operational information & No \\
\hline
\end{tabular}




\begin{tabular}{|c|c|c|c|c|c|c|c|}
\hline \multirow{10}{*}{$\begin{array}{l}\text { C5. Nature of the } \\
\text { industry }\end{array}$} & $\begin{array}{l}\text { Uncertainty of the air cargo handling } \\
\text { industry }\end{array}$ & $\mathrm{x}$ & $\mathrm{x}$ & & $\mathrm{x}$ & $\begin{array}{l}\text { The nature of air cargo demand is volatile and uncertain (Totamane et } \\
\text { al., 2012; Amaruchkul et al., 2011; Wu, 2011; Popescu et al., 2006). }\end{array}$ & No \\
\hline & $\begin{array}{l}\text { Technical and mechanical problems with } \\
\text { aircraft }\end{array}$ & $\mathrm{x}$ & $\mathrm{x}$ & & $\mathrm{x}$ & This causes delays and sometimes flight cancellations & No \\
\hline & Delays due to customs & $\mathrm{x}$ & $\mathrm{x}$ & & $\mathrm{x}$ & $\begin{array}{l}\text { These are mainly caused by faulty documentation, problems at the } \\
\text { customs clearance process, etc. }\end{array}$ & No \\
\hline & $\begin{array}{l}\text { Delays in incoming freight for outbound } \\
\text { cargo or vice-versa due unforeseen } \\
\text { complications }\end{array}$ & $\mathrm{x}$ & $\mathrm{x}$ & & $\mathrm{x}$ & $\begin{array}{l}\text { Delays in outbound cargo are due to trucks late arrival. Delays in } \\
\text { inbound cargo are due to aircrafts' late arrivals. }\end{array}$ & No \\
\hline & $\begin{array}{l}\text { Heterogeneity of freights that require } \\
\text { manpower-intensive operations }\end{array}$ & & $\mathrm{x}$ & & $\mathrm{x}$ & $\begin{array}{l}\text { Due to the heterogeneity factor in customer demand (Kalchschmidt et } \\
\text { al., 2006). Cargo with excess dimensions, excess weight or that require } \\
\text { special handling }\end{array}$ & Yes \\
\hline & $\begin{array}{l}\text { Global service parameters and global } \\
\text { contracts }\end{array}$ & $\mathrm{x}$ & & & $\mathrm{x}$ & $\begin{array}{l}\text { Airlines implement operational strategies globally, unlike several years } \\
\text { ago when issues were dealt locally }\end{array}$ & No \\
\hline & $\begin{array}{l}\text { Health \& Safety - minded approach for } \\
\text { planning workforce }\end{array}$ & & $x$ & & $x$ & $\begin{array}{l}\text { ACHCs have to ensure that the right amount of workforce with the right } \\
\text { set of skills is employed, so as to conduct operations safely }\end{array}$ & Yes \\
\hline & $\begin{array}{l}\text { Diversity of SLAs that ACHCs have to } \\
\text { adhere to }\end{array}$ & & $\mathrm{x}$ & $\mathrm{x}$ & $\mathrm{x}$ & $\begin{array}{l}\text { This is in part due to the heterogeneity factor in customer demand } \\
\text { (Kalchschmidt et al., 2006) }\end{array}$ & Yes \\
\hline & Lack of physical space in aircrafts & $x$ & & & $x$ & This is due to inaccuracy of capacity forecasts & No \\
\hline & $\begin{array}{l}\text { Volatile show-up rate of shippers/freight } \\
\text { forwarders }\end{array}$ & $\mathrm{x}$ & $\mathrm{x}$ & & $\mathrm{x}$ & Also identified by Popescu et al. (2006) & No \\
\hline \multirow{5}{*}{ C6. Outermost } & World recession & $\mathrm{x}$ & & & $\mathrm{x}$ & $\begin{array}{l}\text { "Root cause of all problems in the air cargo industry" (Operations } \\
\text { Manager) }\end{array}$ & No \\
\hline & $\begin{array}{l}\text { Changes on relevant governments' } \\
\text { regulations, policies, laws }\end{array}$ & $\mathrm{x}$ & $\mathrm{x}$ & & $\mathrm{x}$ & $\begin{array}{l}\text { E.g. unanticipated changes in security regulations, which translates into } \\
\text { incorporation of additional operations at ACHCs. This factor causes some } \\
\text { business downturns as well }\end{array}$ & No \\
\hline & Fluctuation in commodities prices & $\mathrm{x}$ & & & $\mathrm{x}$ & Macroeconomic factor & No \\
\hline & $\begin{array}{l}\text { Downturn of business in imports and } \\
\text { exports }\end{array}$ & $x$ & & & $\mathrm{x}$ & Macroeconomic factor & No \\
\hline & The weather & $\mathrm{x}$ & & & $\mathrm{x}$ & $\begin{array}{l}\text { Bad weather can cause delays in in/outbound cargo. It can cause } \\
\text { damages to the freight. }\end{array}$ & No \\
\hline \multirow{3}{*}{ C7. Processes } & Ineffective demand forecasting process & $\mathrm{x}$ & $\mathrm{x}$ & $x$ & & See Section 4 & Yes \\
\hline & High amounts of manual work & & $\mathrm{x}$ & $\mathrm{x}$ & $\mathrm{x}$ & $\begin{array}{l}\text { The incompatibility of systems between airlines and ACHCs often } \\
\text { translates in double or even triple entry of data, or in having to control } \\
\text { KPIs manually. }\end{array}$ & Yes \\
\hline & $\begin{array}{l}\text { Approval process for hiring new staff is } \\
\text { very long }\end{array}$ & & $\mathrm{x}$ & $\mathrm{x}$ & & $\begin{array}{l}\text { Management approval is a 'bottle-neck' (Human Resources Manager) for } \\
\text { the operation }\end{array}$ & Yes \\
\hline
\end{tabular}




\begin{tabular}{|c|c|c|c|c|c|c|c|}
\hline & $\begin{array}{l}\text { Documentation mistakes due to manual } \\
\text { work }\end{array}$ & & $x$ & $x$ & & $\begin{array}{l}\text { An issue that was also identified by Popescu et al. (2006), which causes } \\
\text { delays in operations }\end{array}$ & Yes \\
\hline & Balance between SLAs and 'priority' cargo & & $\mathrm{x}$ & $x$ & $x$ & $\begin{array}{l}\text { E.G. when a 'blood consignment' comes in, operations managers have to } \\
\text { ensure that it is handled with priority without jeopardising the SLAs with } \\
\text { other customers. }\end{array}$ & Yes \\
\hline & Health \& Safety issues with cargo & & $\mathrm{x}$ & $x$ & $\mathrm{x}$ & $\begin{array}{l}\text { The case of hazardous materials that requires special handling, thus, } \\
\text { manpower-intensive operations. }\end{array}$ & Yes \\
\hline & $\begin{array}{l}\text { Contract creeps: certain extra-ordinary } \\
\text { services that } A C H C s \text { do for airlines at no } \\
\text { charge }\end{array}$ & & $\mathrm{x}$ & $x$ & $x$ & $\begin{array}{l}\text { Although sometimes those services are time-consuming/manpower- } \\
\text { intensive, airlines are not willing to be charged for that because they see } \\
\text { it as natural part of process. }\end{array}$ & Yes \\
\hline & $\begin{array}{l}\text { Issues and mistakes with built-up and } \\
\text { break-down of containers }\end{array}$ & & $x$ & $x$ & $x$ & $\begin{array}{l}\text { Wrong built-up and break-down of containers translates into more } \\
\text { manpower hours. }\end{array}$ & Yes \\
\hline \multirow{3}{*}{ C8. Staff } & The quality of staff at the operations level & & $\mathrm{x}$ & $x$ & & $\begin{array}{l}\text { The quality of operational staff is not as good as it should or could be, } \\
\text { because ACHC has only one workforce supplier (recruiting agency) }\end{array}$ & Yes \\
\hline & $\begin{array}{l}\text { The level of lost hours/absences due to } \\
\text { sickness }\end{array}$ & & $x$ & $x$ & $x$ & $\begin{array}{l}\text { According to operations managers and HR staff, this is one factor that } \\
\text { directly impacts on workforce management due to the short notice at } \\
\text { which staff report absence }\end{array}$ & No \\
\hline & Unionized workforce & & $\mathrm{x}$ & & $\mathrm{x}$ & $\begin{array}{l}\text { Strict parameters of union agreements that } \mathrm{ACHCs} \text { are obligated to } \\
\text { adhere to }\end{array}$ & No \\
\hline C9. Supply chain & $\begin{array}{l}\text { The airlines' customers: the next link } \\
\text { downstream in the air cargo supply chain }\end{array}$ & $x$ & & & $x$ & $\begin{array}{l}\text { There are customers who suddenly turn down or increase business, } \\
\text { which translates into considerable variances between forecasted and } \\
\text { actual tonnage to handle }\end{array}$ & No \\
\hline \multirow{2}{*}{ C10. Training } & $\begin{array}{l}\text { Lack of administration and planning skills } \\
\text { of operations managers }\end{array}$ & $x$ & $x$ & $x$ & & $\begin{array}{l}\text { "This industry is not blessed with an abundance of quality management" } \\
\text { (Senior Manager). Skilful in dealing with people but not at the } \\
\text { administration side of things. }\end{array}$ & Yes \\
\hline & $\begin{array}{l}\text { Lack of training in the use of different } \\
\text { airlines information systems }\end{array}$ & & $x$ & $x$ & & $\begin{array}{l}\text { The problems derived from this factor, causes over-consumptions of } \\
\text { valuable manpower hours. }\end{array}$ & Yes \\
\hline
\end{tabular}

Table 2. Analysis of factors influencing forecast accuracy and workforce management. 


\section{Results of the study: propositions}

The interconnection of factors identified and analyzed in the last section was the necessary step to develop the foundations of the following theoretical arguments, which are induced as a logical consequence of the interpretation of data and some of the findings in the literature review. It is important to emphasize that the following propositions are made exclusively in the framework of the air cargo handling industry.

Proposition 1. Internal information flow processes are as important as external ones.

Information flow related factors under categories 1 and 2 indicate a consistent impact on forecast accuracy and on workforce management, either from an internal or an external source. Provided that information flow processes imply collaboration (Aviv, 2001), this finding differs from the studies of Nakano (2009) and Ellinger et al. (2000) who claimed that collaboration internally is more beneficial for operational performance than collaboration externally (see Section 2.3.1).

Proposition 2. Collaboration tends to mitigate complexities caused by the unanticipated and heterogeneous customer demands.

Several factors of unanticipated and heterogeneous nature in categories 1 and 5 that render into a number of operational complexities could be tackled through the implementation of an external information flow process with Airlines. Nevertheless, although it is generally accepted that collaboration with supply chain partners and sharing of information is a positive practice, it cannot be assured that an increase in information availability will reduce forecast inaccuracy (Ramanathan, 2012) caused by the unanticipated and heterogeneous customer demands.

Proposition 3. Heterogeneity factor in customer demand increases amounts of error-prone and time-consuming manual work.

In addition to the incompatibility of systems between Airlines and ACHCs as revealed in some factors in categories 4 and 7; the huge diversity of customer demands in some other factors of categories 1, 5 and 7, indicate a difficulty to standardize business and operations 
processes so as to avoid the high amounts of manual work, which cause a lot of mistakes and time-wasting.

Proposition 4. Weaknesses in business and operations processes primarily affect workforce management.

This can be visually confirmed on the analysis of category 7 , there is a clear bias for all the factors on this category to affect workforce management. The only exception is the demand forecasting process per se, which affects forecast accuracy directly.

Proposition 5. Incompatibility of processes between and within the different players of the air cargo supply chain tends to affect forecasts accuracy and workforce management equitably.

The analysis of various factors in categories 1, 4 and 7 corroborate this proposition. This indicates that in order to attain improvements in both aspects, internal and external processes have to be optimized, standardized or implemented.

Proposition 6. Forecast accuracy tends to be more affected by the human factor at the managerial level, whereas workforce management tends to be more affected by the human factor at the operational level.

It can be ascertained at this point, that a lot of processes in this industry are very humanintensive and there is no full reliance on IT systems, so that at both the managerial and the operational levels, some critical processes are being done manually. For instance: the forecasting process which directly affects forecast accuracy is done by managerial staff (see Section 4); and the various terminal operations processes (any physical cargo handling activity) which directly affect workforce management, are done by operational staff.

Proposition 7. Long-term collaboration with Airlines does not improve forecasting accuracy.

Contrarily to the results of the study by Stapleton et al. (2006), who argues that an inaccurate forecasting is a consequence of a lack of long-term planning and collaboration between supply chain partners, this research has found that long-term plans of the airlines are generally 
not reliable according to the views of experienced forecasters at ACHCs and to the Airlines representatives themselves.

Proposition 8. Short-term collaboration with Airlines positively influences forecasting accuracy.

It can be induced from the analysis in the last section that, besides the daily air cargo demand uncertainty, the complexities in air cargo operations primarily occur in the short-term as per several factors in categories $1,2,4,5,7,10$ and even 6 . Thus, an active collaboration with Airlines in the short-term would significantly improve the forecast accuracy.

Proposition 9. External 'outermost' factors directly affect forecasting accuracy.

Evidently, the five factors categorized as 'outermost' (category 6) in the previous analysis have a, perhaps not immediate, but an inevitable and direct impact on demand forecasting accuracy. These factors are without question, totally out of the control of ACHCs and Airlines.

Proposition 10. A global business environment does not improve forecasts accuracy.

In today's global economic environment (Hill, 2011), it could be argued that provided the ongoing globalization process of every industry, customer demand is homologating, making it more easily predictable. However, contrary to expectations, this study has found that in the air cargo handling industry this is not the case. Some factors identified in categories 1, 3 and 5 refer to the use of global contracts and service parameters and to the huge size of today's Airlines' structure, so that there is a lack on the level of attention paid to local issues, hampering thereby forecasts accuracy.

Proposition 11. Forecasting accuracy leads to workforce planning efficiency.

At this stage it can be determined that improvements in air cargo demand forecasting will allow to precisely calculate the number of staff to roster, narrowing thereby the gap between rostered and actual hours worked. This makes the workforce planning efficient, contributing to mitigate the cost-related problems generated by the factors in category 3 . 
Proposition 12. Forecasting accuracy causes simplification of workforce management.

It is the general view of all the people involved in operations management at the case-study $\mathrm{ACHC}$, that if the exact number and characteristics of the cargo to handle were known in advance, a big portion of the complexities in workforce management could be very well overcome. Besides, the previous analysis suggests, as per several factors in categories 1, 5, 7, 9 and 10, that such an accuracy level in demand forecasts could be achieved through the implementation of a collaborative forecasting approach or a structured process to incorporate effective judgmental adjustments to demand forecasts.

\section{Recommendations and discussion}

In accordance with Propositions 11 and 12 in the last section, forecasting accuracy of air cargo demand has a positive impact on workforce management. Hence, in order to develop a series of appropriate recommendations, only the factors directly affecting forecast accuracy were untangled from the analysis on Section 6. Out of those, the ones that presented potential to be managed by ACHCs were extracted, uncovering 9 factors, which the following recommendations will address.

Factor 1. Lack of communication between ACHCs and Airlines

\begin{tabular}{|l|l|}
\hline \multicolumn{1}{|c|}{ Recommendations from the literature } & \multicolumn{1}{c|}{ Recommendations from the practice } \\
\hline $\begin{array}{l}\text { Segmentation approach for collaboration: } \\
\text { to implement a collaborative approach } \\
\text { with only a critical number of customers, } \\
\begin{array}{l}\text { not with all of them, in order to achieve an } \\
\text { effective implementation. }\end{array}\end{array}$ & $\begin{array}{l}\text { Decentralize communication with Airlines: } \\
\text { In practice, the limited communication } \\
\text { between ACHCs and Airlines is } \\
\text { centralized at the senior management level } \\
\text { (see Section 4), so that ACHCs should } \\
\text { delegate it towards the operational staff } \\
\text { who certainly have a better overview of } \\
\text { the short-term operational problems. This } \\
\text { is also consistent with Proposition } 8 .\end{array}$ \\
\hline
\end{tabular}


Factor 2. Lack of a formal information flow process from Airlines towards ACHCs

Factor 3. Unanticipated nature of extra-ordinary customer requirements

\section{Recommendations from the literature}

\section{Keep collaboration simple:}

There is no need to spend money and resources in the implementation of fancy software for collaboration activities, simple existing communication methods such as e-mail and telephone are more than enough in order to start working on collaborative forecasting. This aspect is mentioned by Barratt (2004) as well.

\section{Implement non-disclosure-agreements:}

Non-disclosure agreements will even encourage Airlines to share their information (Li \& Zhang, 2008) or to establish a formal information flow process towards ACHCs.

\section{Recommendations from the practice}

\section{Seek PHP certifications:}

There is a scheme observed in practice called PHP (Preferred Handling Partner), which is a certification granted by Airlines to ACHCs with the intention of standardize the air cargo handling service provided by the ACHCs and improve its reliability and quality. This represents a major solution to the absence of collaboration between Airlines and ACHCs that would certainly be translated into optimization of demand forecast accuracy as indicated in Proposition 2. So, ACHCs should strive to obtain a PHP certification from its major customers at least, which is consistent with the segmentation approach suggested by Barrat (2004).

Factor 4. Quality of the cargo information that come from airlines

\begin{tabular}{|l|l|}
\hline Recommendations from the literature & $\begin{array}{l}\text { Recommendations from the practice } \\
\text { Implement electronic airway bills: }\end{array}$ \\
$\begin{array}{l}\text { Electronic AWBs allow ACHCs to get } \\
\text { cargo information before the freight } \\
\text { arrives, so that an accurate planning of } \\
\text { resources can be done. A couple of } \\
\text { Airlines are already implementing them } \\
\text { (Senior Manager), but it's a solution that } \\
\text { needs to be fine-tuned. }\end{array}$ \\
\hline
\end{tabular}


Factor 5. ACHCs predominantly deal with local cargo management rather than with senior management from the Airlines

\section{Recommendations from the literature $\quad$ Recommendations from the practice}

\section{Use the Airlines' 'suffering' to the ACHC's advantage:}

"Airlines also suffer from inaccurate forecasting" (Airline Representative), so it would be worth it to convince Airlines that a better match between supply and demand, in this case the match between resources (manpower) and demand for air cargo, could be achieved by means of the jointly development of "long-term demand projections rather than rely on separate, independently generated forecasts" (Stank, et al., 2001, p. 32).

Factor 6. Lack of communication between ACHCs' business units/hubs at different locations

\begin{tabular}{|c|c|}
\hline Recommendations from the literature & Recommendations from the practice \\
\hline Practice effective communication: & \\
\hline $\begin{array}{l}\text { Immediate and clear communication is } \\
\text { vital between internal (hubs within the } \\
\text { same ACHC) and external (customers, } \\
\text { freight forwarders and Airlines) supply } \\
\text { chain partners, in order to cope with any } \\
\text { changes against the forecasted demand. } \\
\text { This is supported by Stapleton, et al. } \\
\text { (2006). }\end{array}$ & \\
\hline
\end{tabular}

Factor 7. Different information systems used by the different Airlines

\section{Recommendations from the literature $\quad$ Recommendations from the practice}

\section{Standardize the internal processes first:}

This is an initiative observed in the case-study ACHC, which is partially supported by Stank, et al. (2001), so as to enable ACHCs to focus on dealing with the variety of information systems used by the different airlines once their internal processes have been standardized. 
Factor 8. Ineffective demand forecasting process

\section{Recommendations from the literature}

Use more than one forecasting technique:

In order to achieve a higher degree of forecasting accuracy with a low margin for error, it is highly recommended to use two or more forecasting techniques simultaneously (Lawrence, et al., 2006; Waddell \& Sohal, 1994).

\section{Identify important drivers of judgmental adjustments in the air cargo industry:}

This significantly enhances effectiveness of judgmental forecasting. For example in the retailing industry such drivers could be: promotions, price changes, weather, inventories, etc. (Fildes, et al., 2009).

\section{Try to increase flight frequency:}

If an accurate demand forecasting of air cargo cannot be achieved, and in the case of cargo volumes being lower than expected, ACHCs should talk to Airlines about the possibility to increase the flight frequency using smaller aircrafts which would positively impact on their operation costs, as proposed by Hsu, et al. (2013).

\section{Formally document the justifications of the judgmental adjustments made:}

A good practice that is stressed by Fildes \& Goodwin (2007), so as to create a structured procedure to incorporate those adjustments into the forecasting method used. This documentation of reasons for adjusting judgmentally is beneficial because:

- $\quad$ It makes forecasters to feel more liable with the forecasting process.

- $\quad$ It increases the level of analysis that forecasters do on the specific reasons as to why judgmental adjustments have been made.

- It stimulates the readiness to learn when to apply judgmental adjustments in the forecasting process.

- It avoids the possibility of using judgment tendentiously. 
Factor 9. Lack of administration and planning skills of operations managers

\begin{tabular}{|c|c|}
\hline Recommendations from the literature & Recommendations from the practice \\
\hline Train forecasters extensively: & \\
\hline $\begin{array}{l}\text { Although it is pretty obvious, staff that is } \\
\text { responsible to create forecasts, must be } \\
\text { well trained in order to ensure a high level } \\
\text { of accuracy in the forecasts they produce } \\
\text { (Fildes, et al., 2009). }\end{array}$ & \\
\hline Prioritize large adjustments: & \\
\hline $\begin{array}{l}\text { Managers should pay special attention to } \\
\text { larger adjustments, because according to } \\
\text { Fildes, et al. (2009) these tend to be more } \\
\text { efficient and result in greater } \\
\text { improvements in accuracy than smaller } \\
\text { adjustments. The main reason is because } \\
\text { the information of large adjustments tends } \\
\text { to come from more reliable sources, so } \\
\text { that smaller adjustments should actually be } \\
\text { avoided. ACHCs could implement some } \\
\text { simple tool or function in excel or in their } \\
\text { forecasting system that prevents them } \\
\text { from adjusting the forecasts below certain } \\
\text { percentage in order to comply with this } \\
\text { measure (Fildes, et al., 2009). }\end{array}$ & \\
\hline Monitor forecasters' degree of trust: & \\
\hline $\begin{array}{l}\text { Managers should be very careful with their } \\
\text { own degree of trust in their own } \\
\text { judgements, since this could become an } \\
\text { issue for the forecast accuracy if the } \\
\text { degree of trust is excessive (Fildes, et al., } \\
\text { 2009). }\end{array}$ & \\
\hline
\end{tabular}

\section{Conclusion}

In summary, the outcomes of this research rendered into the following four main contributions to the literature in the framework of the air cargo handling industry: 
- The identification and analysis of the factors affecting forecast accuracy and workforce management.

- The corresponding interpretation of that analysis in the form of theoretical propositions aiming to expose the relationship between demand forecasting and operational performance in terms of workforce management.

- The identification of a range of additional hidden factors, different from forecast inaccuracy, that affects workforce management, which could be considered as by-products of the research.

- The generation of recommendations to be applied in the business practice striving to improve demand forecasting and consequently to improve workforce management.

This research is limited to a single case study, which is likely to affect the generalization and representativeness of the new theories that have been induced qualitatively. However, in order to overcome this limitation, more diversified quantitative exploration is recommended, which could be the subject of another research in future. Furthermore, even though this study did not propose a unique method or analytical model to improve workforce management through a quantitative demand forecasting process, the outcome of the research should have either uncovered several opportunity areas, or serve as an awareness tool for practitioners in order for them to develop further ideas that can be translated into improvements of operations at their different settings and business environments.

\section{References}

Acar, Y. \& Gardner Jr., E. S. (2012) 'Forecasting method selection in a global supply chain'. International Journal of Forecasting, 28(4), pp. 842-848

Adebanjo, D. (2009) 'Understanding demand management challenges in intermediary food trading: a case study'. Supply Chain Management: An International Journal, 14(3), pp. 224233

Amaruchkul, K. \& Lorchirachoonkul, V. (2011) 'Air-cargo capacity allocation for multiple freight forwarders'. Transportation Research Part E, 47(1), pp. 30-40

Aviv, Y. (2001) 'The Effect of Collaborative Forecasting on Supply Chain Performance'. Management Science, 47(10), pp. 1326-1343

Barratt, M. (2004) 'Understanding the meaning of collaboration in the supply chain'. Supply Chain Management: An International Journal, 9(1), pp. 30-42

Becker, B. \& Wald, A. (2010) 'Challenges and success factors of air cargo revenue management'. Journal of Revenue and Pricing Management, 9(1-2), pp. 171-184 
BOEING (2012) World Air Cargo Forecast, [Online]. Available at: http://www.boeing.com/boeing/commercial/cargo/ (Accessed: 7 April 2013)

Bryman, A. \& Bell, E. (2011) Business Research Methods. 3rd edn ed. New York: Oxford University Press.

Chang, Y.-H., Yeh, C.-H. \& Wang, S.-Y. (2007) 'A survey and optimization-based evaluation of development strategies for the air cargo industry'. International Journal of Production Economics, Volume 106, pp. 550-562

Chen, S.-C., Kuo, S.-Y., Chang, K.-W. \& Wang, Y.-T. (2012) 'Improving the forecasting accuracy of air passenger and air cargo demand: the application of back-propagation neural networks'. Transportation Planning and Technology, 35(3), pp. 373-392

Chew, E.-P., Huang, H.-C., Johnson, E. L.; Nemhauser, G. L.; Sokol, J. S. \& Leong, C.-H. (2006) 'Short-term booking of air cargo space'. European Journal of Operational Research, 174(3), pp. 1979-1990

Chopra, S. \& Meindl, P. (2013) Supply Chain Management. 5th edn ed. Essex: Pearson.

Chou, T.-Y., Liang, G.-S. \& Han, T.-C. (2013) 'Application of fuzzy regression on air cargo volume forecast'. Quality \& Quantity, 47(2), pp. 897-908

Davis, D.F. and Mentzer, J.T. (2007), "Organizational factors in sales forecasting management", International Journal of Forecasting, Vol. 23 No. 3, pp. 475-95.

Davydenko, A. \& Fildes, R. (2013) 'Measuring forecasting accuracy: The case of judgmental adjustments to SKU-level demand forecasts'. International Journal of Forecasting, 29(3), pp. $510-522$

Ellinger, A. E., Daugherty, P. J. \& Keller, S. B. (2000) 'The Relationship between Marketing/Logistics Interdepartmental Integration and Performance in U.S. Manufacturing Firms: An Empirical Study'. Journal of Business Logistics, 21(1), pp. 1-22

Ernst, A., Jiang, H., Krishnamoorthy, M. \& Sier, D. (2004) 'Staff scheduling and rostering: A review of applications, methods and models'. European Journal of Operational Research, 153(1), pp. 3-27

Fildes, R. \& Goodwin, P. (2007) 'Against Your Better Judgment? How Organizations Can Improve Their Use of Management Judgment in Forecasting'. Interfaces, 37(6), pp. 570-576

Fildes, R. \& Kingsman, B. (2011) 'Incorporating demand uncertainty and forecast error in supply chain planning models'. Journal of the Operational Research Society, 62(3), pp. 483500

Fildes, R., Goodwin, P., Lawrence, M. \& Nikolopoulos, K. (2009) 'Effective forecasting and judgmental adjustments: an empirical evaluation and strategies for improvement in supplychain planning'. International Journal of Forecasting, 25(1), pp. 3-23

Gold, R. (1958). "Roles in sociological field observation." Social Forces, 36, 217-213. 
Hill, C. W. (2011) International Business: Competing in the Global Marketplace. 8th edn ed. New York: McGraw-Hill.

Hsu, C.-I., Chen, Y.-H. \& Chen, W.-T. (2013) 'A study on airlines' differentiated cargo service strategies'. Transport Policy, 25(1), pp. 101-110

Hsu, C-I. and Wang, C-C. (2013) 'Reliability analysis of network design for a hub-and-spoke air cargo network'. International Journal of Logistics Research and Applications, 16 (4), 257 276

Hung, W-H., Lin, C-P. and Ho, C-F. (2014) 'Sharing information in a high uncertainty environment: lessons from the divergent differentiation supply chain'. International Journal of Logistics Research and Applications, 17 (1), 46-63

IATA (2013) International Air Transport Association (IATA). [Online] Available at: http://www.iata.org/publications/airlines-international/april-2010/Pages/06.aspx(Accessed: 29 August 2013)

Kahn, K. B. \& Mentzer, J. T. (1996) 'Logistics and interdepartmental integration'. International Journal of Physical Distribution \& Logistics, 26(8), pp. 6-14

Kalchschmidt, M., Verganti, R. \& Zotteri, G. (2006) 'Forecasting demand from heterogeneous customers'. International Journal of Operations \& Production Management, 26(6), pp. 619638

Kasilingam, R. (1996) 'Air cargo revenue management: Characteristics and complexities'. European Journal of Operational Research, 96(1), pp. 36-44

Lagodimos, A. \& Paravantis, J. (2006) 'Improved heuristic for manpower shift planning with modified shift priorities'. Production Planning \& Control, 17(3), pp. 301-310

Lau, K. H. (2012) 'Demand management in downstream wholesale and retail distribution: a case study'. Supply Chain Management: An International Journal, 17(6), pp. 638-654

Lawrence, M., Goodwin, P., O’Connor, M. \& Önkal, D. (2006) 'Judgmental forecasting: A review of progress over the last 25years'. International Journal of Forecasting, 22(3), pp. 493-518

Lysons, K. \& Farrington, B. (2012) Purchasing and Supply Chain Management. 8th edn ed. Essex: Pearson.

Marmier, F. \& Cheikhrouhou, N. (2010) 'Structuring and integrating human knowledge in demand forecasting: a judgemental adjustment approach'. Production Planning \& Control: The Management of Operations, 21(4), pp. 399-412

McIvor, R. (2008) 'What is the right outsourcing strategy for your process?', European Management Journal, 26(1), pp. 24-34

Nakano, M. (2009) 'Collaborative forecasting and planning in supply chains: The impact on performance in Japanese manufacturers'. International Journal of Physical Distribution \& Logistics Management, 39(2), pp. 84-105

Nelms, D. W. (1999) 'Outsourcing the ground'. Air Transport World, 2(2), pp. 21-23 
Nobert, Y. \& Roy, J. (1998) 'Freight Handling Personnel Scheduling at Air Cargo Terminals'. Transportation Science, 32(2), pp. 295-301

Ou, J., Hsu, V. N. \& Li, C.-L. (2010) 'Scheduling Truck Arrivals at an Air Cargo Terminal'. Production and Operations Management, 19(1), pp. 83-97

Poler, R., Hernandez, J. E., Mula, J. \& Lario, F. C. (2008) 'Collaborative forecasting in networked manufacturing enterprises'. Journal of Manufacturing Technology Management, 19(4), pp. 514-528

Popescu, A., Keskinocak, P., Johnson, E., LaDue, M. \& Kasilingam, R. (2006) 'Estimating Air-Cargo Overbooking Based on a Discrete Show-Up-Rate Distribution'. Interfaces, 36(3), pp. $248-258$

Ramanathan, U. (2012) 'Supply chain collaboration for improved forecast accuracy of promotional sales'. International Journal of Operations \& Production Management, 32(6), pp. 676-695

Rong, A. \& Grunow, M. (2009) 'Shift designs for freight handling personnel at air cargo terminals'. Transportation Research Part E, 45(5), pp. 725-739

Sanders, N. R. (1995) 'Managing the forecasting function'. Industrial Management and Data Systems, 95(4), pp. 12-18

Stank, T. P., Keller, S. B. \& Daugherty, P. J. (2001) 'Supply Chain Collaboration and Logistical Service Performance'. Journal of Business Logistics, 22(1), pp. 29-48

Stapleton, D., B., H. J. \& Ross, J. R. (2006) 'Enhancing supply chain solutions with the application of chaos theory'. Supply Chain Management: An International Journal, 11(2), pp. $108-114$

Suryani, E., Chou, S.-Y. \& Chen, C.-H. (2012) 'Dynamic simulation model of air cargo demand forecast and terminal capacity planning'. Simulation Modelling Practice and Theory, 28(1), pp. 27-41

Totamane, R., Dasgupta, A. \& Rao, S. (2012) 'Air Cargo Demand Modeling and Prediction'. IEEE Systems Journal, PP(99), pp. 1-11

Waddell, D. \& Sohal, A. S. (1994) 'Forecasting: The Key to Managerial Decision Making'. Management Decision, 32(1), pp. 41-49

Ward, D. (1996) 'Workforce Demand Forecasting Techniques'. Human Resource Planning, 19(1), pp. 54-55

Win, A. (2008) 'The value a 4PL provider can contribute to an organisation'. International Journal of Physical Distribution \& Logistics Management, 38(9), pp. 674-684

Wook Kim, S. (2006) 'Effects of supply chain management practices, integration and competition capability on performance'. Supply Chain Management: An International Journal, 11(3), pp. 241-248

Wu, Y. (2011) 'Modelling of containerized air cargo forwarding problems under uncertainty'. Journal of the Operational Research Society, 62(7), pp. 1211-1226 
Yan, S., Chen, C.-K. \& Chen, C.-H. (2006) 'Cargo Terminal Shift Setting and Manpower Supplying in Short-term Operations'. Journal of Marine Science and Technology, 14(2), pp. $109-118$

Zhang, A. \& Zhang, Y. (2002) 'A model of air cargo liberalization: passenger vs. all-cargo carriers'. Transportation Research Part E, 38(3), pp. 175-191 


\section{Appendix A}

\section{SENIOR MANAGERS/DIRECTORS}

- Main transforming resource (manpower) is planned according to the budgets of tonnages to handle?

- Where do these budgets come from? => Customer contracts?

- Who carries the responsibility to determine the amount of tonnages to be handled per month? The airlines or ACHC?

- According to the scorecards the biggest variations between total tonnages handled and budget are in LGW followed by B552, B551 and B550 (in that particular order).

- What is the variance tolerance between budgets and actual handled tonnages?

- How do you plan your resources/manpower?

- How are the rosters of manpower hours created? And who creates them?

- In which building, or with what customer, do you think ACHC is facing the biggest issues caused by big variations in the demand for cargo to handle? (demand forecast accuracy)

- Has it always been like that? Or has the situation changed between customers over time?

- What are the biggest competitors of ACHC?

- According to the literature about air cargo demand management, there are two broad operational issues which are quite challenging: capacity management and resource management. Which one of them is more challenging for $\mathrm{ACHC}$ ?

- Forecasting methods:

$\checkmark$ trend factors

$\checkmark$ seasonality indices

$\checkmark$ historical payload data

- Does ACHC use an overbooking practice to compensate for no-shows, cancellations and variations in the demand?

- Shipper behaviour is not measured or is that the KPI of "Flight Utilisation"?

- Which building/business unit has the biggest negative impact? (in terms of profit, losses, waste of resources, etc.)

\section{FORECASTERS/OPERATIONS MANAGERS}

- What is your relationship with the sales department?

- What kind of information do they share with you?

- Do you know about the long-term plans of the airlines or their cargo capacity in future?

- Is there such thing as a 'formal line of collaboration' with the airlines?

- A closer collaboration with which customers (airlines) would make more sense in terms of profit?

- What is the level of collaboration with the different airlines?

- How do you plan your workforce, weekly, monthly, yearly?

- What is the lead-time for recruiting new staff?

- Extreme cases in variance differences have cost implications, so could a better forecasting have helped to run the operations at a lower cost/more profit? Because employing part-time staff from the agency and paying overtime is presumably quite expensive.

- To your opinion, which "strategy" is more costly? running short of capacity (workforce) or overcapacity?

- Forecasting processes of the different airlines?

- Factors that affect accuracy of the forecasts? 
- What other factors, apart from inaccuracy of the forecasts, can have a negative influence in the planning of the workforce needed to meet demand?

- What are your main issues in terms of operations management?

- Do you have a problem in the management of your resources (workforce) to accurately meet demand?

- What are the main issues that prevent $\mathrm{ACHC}$ from accurately meet the demand for cargo to move?

- Do you think the problem can be attributed to an inaccurate forecasting of cargo to move?

- What kind of problems do you usually face in regards with the management of your workforce?

- Are you directly responsible to plan the number of staff that you will require per week/month?

- I understand the rosters of hours come directly from finance, how do you use them or what is the process that you follow to translate those amount of hours into the actual number of employees that you require to run your operations?

- Do you think that a better forecasting of the demand for cargo freight, would help you to better manage your workforce? Or to calculate your workforce more accurately?

- To your opinion, what are other factors that influence your manpower management? Is inaccurate forecasting the only one (root cause)?

- To your opinion, which "strategy" is more costly? running short of capacity (workforce) or overcapacity?

- Do the airlines share some kind of 'forecasted cargo volumes to handle' with ACHC?

- Do airlines share their long-term plans with ACHC?

\section{AIRLINES REPRESENTATIVES}

- Do the airlines share some kind of 'forecasted cargo volumes to handle' with ACHC?

- Do airlines share their long-term plans with ACHC?

- If they would do that, do you think those long-term plans would be reliable?

- When you do a new contract with an airline or renew it, how does ACHC know how much volume will be there to handle and whether $\mathrm{ACHC}$ has the required resources in terms of capacity and workforce, to absorb that new contract?

- What or where is the connection between sales and operations?

- What information from the airlines do you actually share with other departments within $\mathrm{ACHC}$ ? i.e. finance, operations, HR?

- How do you translate airlines' requirements into actual demand for cargo freight?

- Is there such thing as a 'formal line of collaboration' between the airlines and ACHC?

- Airlines suffer as well from an inaccurate forecasting, right? (service level, etc.) Inaccurate forecasting $=>$ negatively impacts in the management of the workforce $=>$ negatively impacts on the service level

\section{HUMAN RESOURCE MANAGERS}

- Use of the agency

- Uncertainty in the demand and inaccurate forecasting?

- Agency vs. overtime.

- Do you think you have a problem with the rostering of your workforce?

- Do you think you pay too much over-time and agency staffing?

- What do you think is the reason for that? (root cause)

- What is the lead-time for recruiting new staff? 